\title{
Catalytic Activity of $\mathrm{Ni}_{3} \mathrm{Al}$ Foils in Methanol Reforming
}

\author{
P. Jozwik ${ }^{1, a}$, R. Grabowski ${ }^{2}$ and Z. Bojar ${ }^{1, b}$ \\ ${ }^{1}$ Military University of Technology, Department of Advanced Materials and Technology \\ Kaliskiego 2 St., 00-908 Warsaw 49, Poland. \\ ${ }^{2}$ Institute of Catalysis and Surface Chemistry PAS, Niezapominajek 8 St., 30-239 Cracow, Poland.

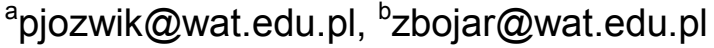

Keywords: $\mathrm{Ni}_{3} \mathrm{Al}$ intermetallic alloy, Thin foils, Methanol decomposition, Hydrogen production, Carbon nanofibres

\begin{abstract}
Intermetallic $\mathrm{Ni}_{3} \mathrm{Al}$-based alloys (doped with zirconium and boron) represent a group of advanced materials with potential outstanding physical and chemical properties (such as high catalytic activity and structural stability in corrosive environments) that make them a considerable candidate for many high-tech applications. In this paper, the catalytic activity of fully dense $\mathrm{Ni}_{3} \mathrm{Al}$ based thin foils (as thin as $50 \mu \mathrm{m}$ ) possessing structures with micrometer or nanometer grain sizes is discussed. The examined material, without any additional catalytic coating, was successfully produced from as-cast coarse-grained sheets by heavy cold rolling and recrystallisation with an appropriately chosen set of parameters. The examination focuses on methanol and methanol/water mixture decomposition into $\mathrm{H}_{2}$ and $\mathrm{CO}$ at temperatures up to $530^{\circ} \mathrm{C}$ in a quartz reactor. Except for these products, a small amount (below $1 \%$ ) of $\mathrm{CO}_{2}$ and dimethyl ether was observed. The catalyzed reaction began effectively at about $400^{\circ} \mathrm{C}$, with a methanol conversion of about $90 \%$ or higher.
\end{abstract}

\section{Introduction}

Ordered $\mathrm{Ni}_{3} \mathrm{Al}$ intermetallic alloys constitute a unique class of metallic materials that show excellent oxidation/corrosion resistance, fairly high melting temperatures, relatively low densities and anomalous strengthening with increasing temperature $[1,2]$.

With respect to the above-mentioned properties of $\mathrm{Ni}_{3} \mathrm{Al}$ alloys, the applications of thin foils may take a special rank. These materials can be used in high-performance applications in the form of honeycomb structures, which have the advantages of light weight, high stiffness and high strength, as compared to bulk Ni-based superalloys. Thus far, we have successfully fabricated thin $\mathrm{Ni}_{3} \mathrm{Al}$ foils by cold rolling commonly casted ingots without additional treatment. The proposed technology allows us to obtain foils with a thickness below $50 \mu \mathrm{m}$, with micro and nanostructures $[2,3]$. Another method for obtaining thin foils (with microcrystalline structures only) was reported by Hirano et al. [4], where directionally solidified ingots were rolled at room temperature. For materials obtained according to this method, the authors confirmed good catalytic properties in methanol decomposition $[5,6]$.

Methanol is expected to be used as an alternative energy source (as a fuel) in the near future because it can be synthesized from biomass, natural gas, coal, etc., which are more abundant than crude oil [6-8]. Additionally, methanol decomposition to hydrogen and carbon monoxide is an endothermic process, and therefore, it allows for the possibility of recovering waste heat from industrial and automobile exhaust gases. Integrated heat-exchanger/reactors can possibly be used to realise this new processing concept - connecting exothermic combustion with endothermic methanol decomposition. The above-mentioned properties of thin $\mathrm{Ni}_{3} \mathrm{Al}$ foils, in particular, their good catalytic properties in the absence of any coating, allow micro-scale power sources (e.g., MEMS, MECS) to be built with energy densities exceeding those of macro-scale devices [9-15].

The main aim of this work is to investigate the influence of $\mathrm{Ni}_{3} \mathrm{Al}$ foil structures (nano and microstructures) on methanol decomposition and to further verify the catalytic activity of materials obtained by author's method [2,3], which differs from that described in the present literature $[5,6]$. 


\section{Experimental}

A nearly single-phase $\mathrm{Ni}_{3} \mathrm{Al}$ intermetallic alloy with the nominal composition of $\mathrm{Ni}-22,1 \mathrm{Al}-$ $0,26 \mathrm{Zr}-0,1 \mathrm{~B}$ (at.\%) was induction-melted from pure elements in high purity argon and cast into a shell mold. The obtained ingot was cut into sheets using a friction saw.

The microcrystalline foils were obtained by cold rolling at room temperature for $95 \%$ cold work without intermediate annealing. For the next step, the prepared material was recrystallisation-treated up to $1100^{\circ} \mathrm{C}$ for up to 1.5 hours in an argon atmosphere. The nanocrystalline foils were obtained by cold rolling at liquid-nitrogen temperature for $98 \%$ cold work and were subsequently annealed up to $700^{\circ} \mathrm{C}$ for $15 \mathrm{~min}$ in an argon atmosphere. More information about the fabrication procedures has been given previously [2,3]. $\mathrm{Ni}_{3} \mathrm{Al}$ foils (in micro and nanocrystalline conditions) obtained by the above-mentioned processing technology were mechanically polished for the next step.

Catalytic experiments of hydrogen production from methanol were performed in a fixed-bed quartz tube reactor. Foils with thickness about $60 \mu \mathrm{m}$, mechanically cut into small pieces ( $6 \times 2 \mathrm{~mm}$, total weight $0.4 \mathrm{~g}$ per each experiment). Before the catalytic experiments, the foils were annealed in a reducing atmosphere, as described in the current literature $[5,6]$. The initial feed mixtures with different feed compositions (methanol, water and helium) were introduced into the reactor at a flow rate of $30 \mathrm{ml} / \mathrm{min}(1.8 \mathrm{l} / \mathrm{h})$. Feed mixtures were obtained by flowing helium through a known mixture of water and methanol at $25^{\circ} \mathrm{C}$ (Tab. 1).

Table 1. The mixtures of $\mathrm{MeOH}$ - water that were used to examine methanol decomposition

\begin{tabular}{|c|c|c|c|c|}
\hline \multirow{2}{*}{ Designation } & \multirow{2}{*}{$\begin{array}{c}\text { Methanol } \\
\text { content } \\
\text { in liquid phase } \\
{[\%]}\end{array}$} & \multicolumn{2}{|c|}{$\begin{array}{c}\text { Calculated partial pressure } \\
\text { in gas phase at } 25^{\circ} \mathrm{C}[\mathrm{kPa}]\end{array}$} & \multirow{2}{*}{$\begin{array}{c}\mathrm{MeOH} / \mathrm{H}_{2} \mathrm{O} \text { partial } \\
\text { pressure ratio }\end{array}$} \\
\cline { 3 - 4 } & 100 & $\mathbf{M e O H}$ & $\mathbf{H}_{2} \mathbf{O}$ & \\
\hline K 100 & 95 & 17.4 & 0 & - \\
\hline K 95 & & 15.6 & 0.4 & 39 \\
\hline
\end{tabular}

The catalytic experiments were carried out at temperatures ranging from $280^{\circ} \mathrm{C}$ to $530^{\circ} \mathrm{C}$. The temperature was elevated every $30 \mathrm{~min}$ by $50^{\circ} \mathrm{C}$, and the products were analysed online by a Quadera 200 mass spectrometer. The yield and selectivity were estimated, using calibration coefficients obtained from an analysis of a known mixture.

Selectivity to a particular product was calculated as the number of moles of the particular product to the sum of all of the product moles, expressed as a percentage. However, the yield of a particular product was calculated as the product of the ratio of methanol conversion and selectivity to the particular product.

The surface morphologies, examined after catalysis, were observed by scanning electron microscopes, Phillips XL 30 and Zeiss Leo 1530, both with secondary electron detectors (SE).

The phase structure of the surface products after catalysis was examined by X-ray diffraction using a Seifert 3003 diffractometer with $\mathrm{CuK}_{\alpha}$ radiation. Spectral interpretation was carried out using Seifert Analyze software and the DHN PDF 2 database. 


\section{Results and discussion}

Catalytic results. As can be seen in Fig. 1, regarding microcrystalline $\mathrm{Ni}_{3} \mathrm{Al}$, the conversion of pure methanol ("K100" - Tab. 1) with increasing temperature is generally rapid and begins at approximately $280^{\circ} \mathrm{C}$. At about $430^{\circ} \mathrm{C}$, the value of methanol conversion reaches about $90 \%$, and at temperatures greater than $480^{\circ} \mathrm{C}$, it stabilises at nearly $100 \%(98,7 \%)$ after only $120 \mathrm{~min}$. The addition of water to the feed mixture changes the temperature dependence of the conversion. An increase in the water content in the mixture improves the conversion. Small amounts of water $(\sim 5 \%)$ result in a small improvement in the methanol decomposition - the process begins earlier and reaches a level of $98 \%$ at temperatures above $430^{\circ} \mathrm{C}$. This is in contrast to the recent literature, where a comparable level of conversion $(98 \%)$ [5, 6] was obtained at a higher temperature - about $520^{\circ} \mathrm{C}$ - for 29 hours. At temperatures similar to those used in our experiment (about $440^{\circ} \mathrm{C}$ ), the authors of the above-cited literature obtained less than $80 \%$ methanol conversion for 65 hours.

On the basis of the results depicted in Fig. 1, only the pure methanol and methanol with a 5\%vol addition of water were chosen for the catalytic experiments with nanocrystalline $\mathrm{Ni}_{3} \mathrm{Al}$ foils. In these two cases, the calculated partial pressure of $\mathrm{MeOH}$ in the feed mixture composition was 17,4 $\mathrm{kPa} \mathrm{MeOH}$ for pure methanol and $15,6 \mathrm{kPa} \mathrm{MeOH}$ for the feed mixture with the added water. Figure $1 \mathrm{~b}$ shows the results of $\mathrm{MeOH}$ conversion on nanocrystalline foils as a function of temperature. As can be seen in Fig. $1 \mathrm{~b}$, in comparison to the microcrystalline $\mathrm{Ni}_{3} \mathrm{Al}$ catalyst, at temperatures lower than $330^{\circ} \mathrm{C}$, the conversion of $\mathrm{MeOH}$ is practically zero. The reaction starts above $330^{\circ} \mathrm{C}$ and develops quickly with increasing temperature. The addition of a small amount of water $(5 \%)$ slightly changes the course of conversion, and the process ends at a level of nearly $100 \%$.
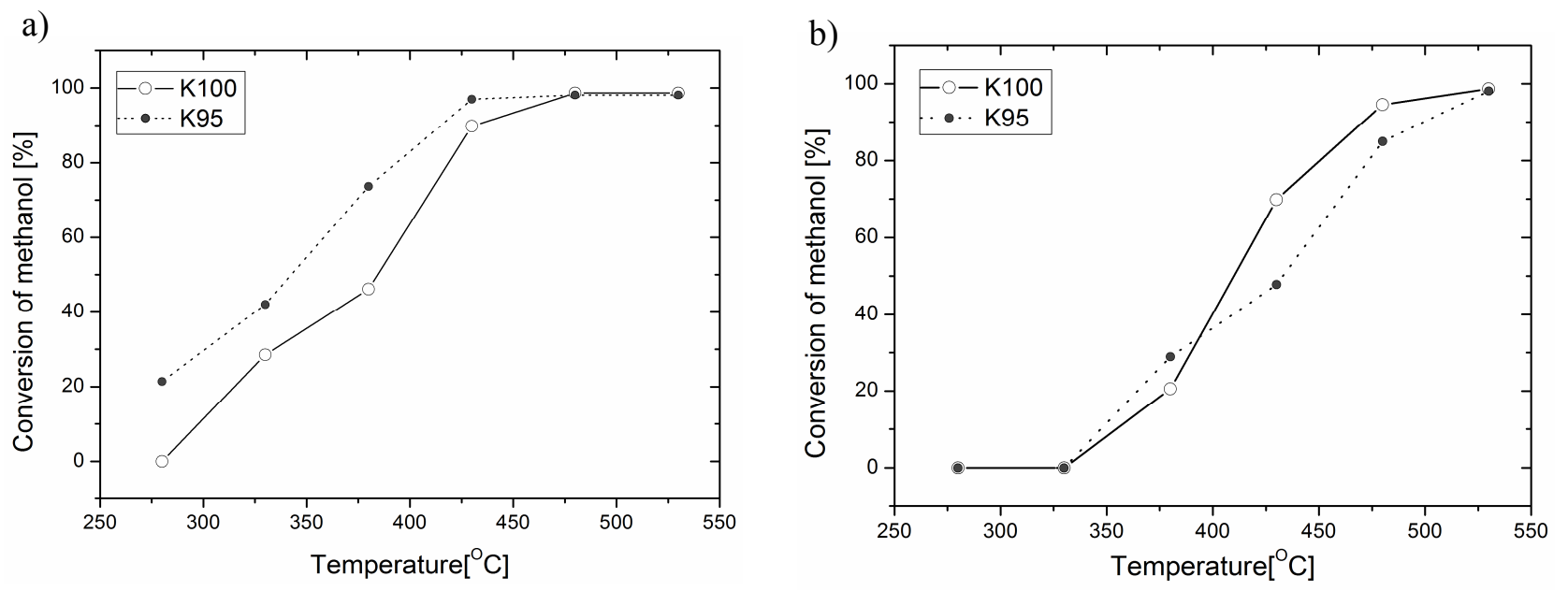

Fig. 1. Conversion of methanol for different feed mixture compositions as a function of temperature on $\mathrm{Ni}_{3} \mathrm{Al}$ micro (a) and nanocrystalline (b) foil catalysts (described in Tab. 1).

In Fig. $2 a$ and $2 b$, the selectivities to the main products obtained on the micro and nanocrystalline foils are shown. For both feed mixture compositions, $\mathrm{CO}$ and $\mathrm{H}_{2}$ are the main products, and for the case of the microcrystalline $\mathrm{Ni}_{3} \mathrm{Al}$ catalyst, we observed similar curves for both feed mixtures. Whereas for nanocrystalline foils, the relative concentration of $\mathrm{CO}$ and $\mathrm{H}_{2}$ depends on the feed mixture composition and can be easily observed at temperatures above $400^{\circ} \mathrm{C}$ - the selectivity of hydrogen in these conditions was even higher than the selectivity of carbon monoxide. 
a)

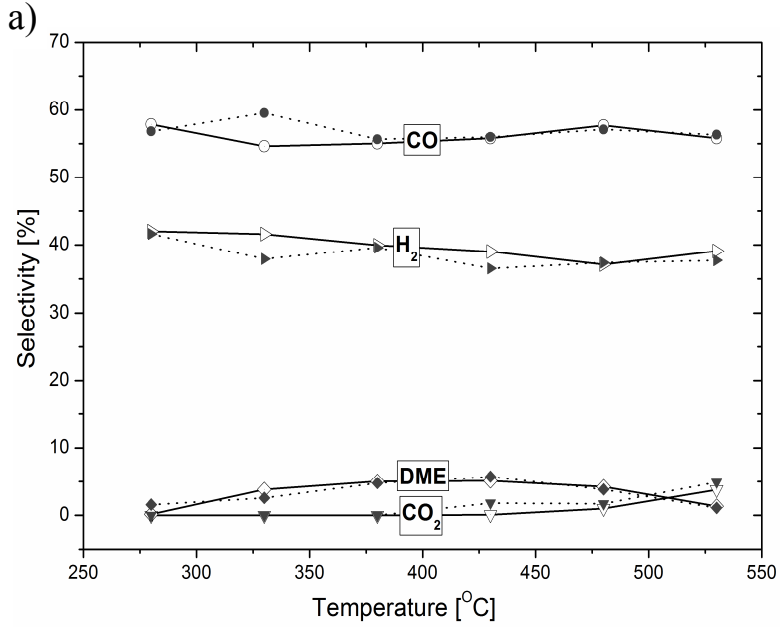

b)

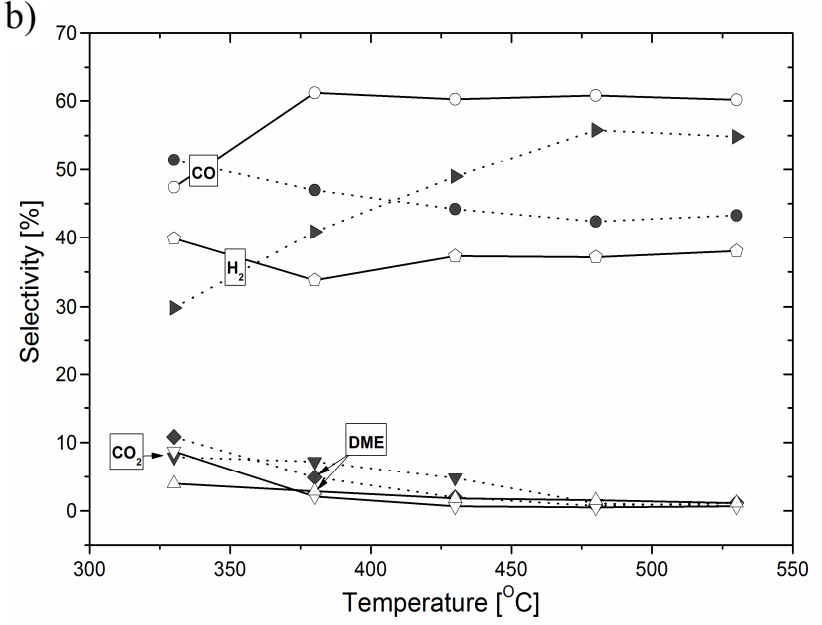

Fig. 2. Selectivity to the main products $\left(\mathrm{H}_{2}, \mathrm{CO}, \mathrm{DME}\right.$, and $\left.\mathrm{CO}_{2}\right)$ for the two feed mixture compositions (open markers and solid lines - pure methanol: "K100", gray markers and dotted lines - methanol $+5 \%$ water: "K95") as a function of temperature for $\mathrm{Ni}_{3} \mathrm{Al}$ microcrystalline (a) and nanocrystalline (b) foils.

The clean and lustrous surfaces of the $\mathrm{Ni}_{3} \mathrm{Al}$ foils, as observed before the experiment, are covered with a film substance that looks like soot after the catalytic examination. The surface SEM observations show the presence of carbon nanofibres and metal-like contrast nanoparticles, deposited during methanol decomposition (Fig. 3 and 4). The microcrystalline foils observed in the secondary electron (SE) mode possess individual carbon nanofibres with a predominant average diameter below $50 \mathrm{~nm}$ (Fig. 3). For the case of the nanocrystalline foils, we observed different (microcrystalline) shapes and nanofibre dimensions. A bimodal size of carbon nanofibres was visible - well twisted, relatively thick fibres of about $120 \mathrm{~nm}$ in diameter and smaller ones of about $30 \mathrm{~nm}$ (Fig. 4). For both cases of material structures, we obtained carbon nanofibres much smaller than those reported in the literature [5,6]. The metal-like nanoparticles were found to be nanoparticles of pure nickel built in a carbon nanofibre structure. The existence of both discussed components on the foil surfaces after the decomposition reaction, for example, on the $\mathrm{Ni}_{3} \mathrm{Al}$ microcrystalline foil, was confirmed by X-ray diffraction analysis (Fig. 5). Metal-like nanoparticles are visible even in SE images at large magnification (for example, Fig. 3b).
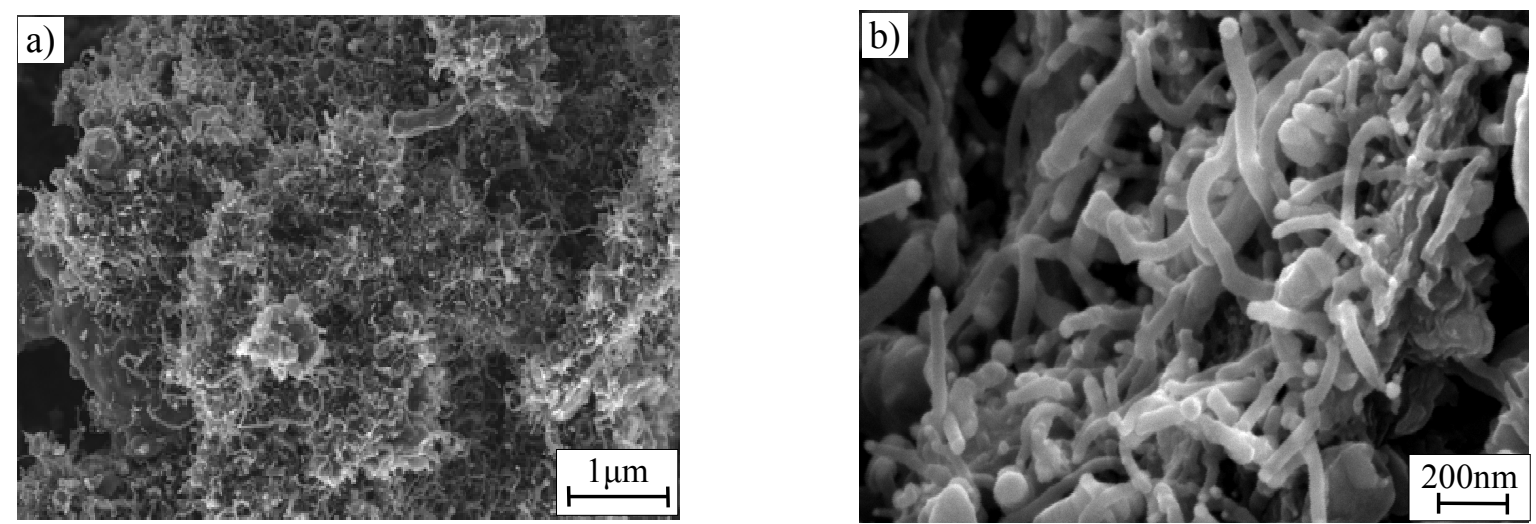

Fig. 3. Morphology of carbon nanofibres (SEM - SE) deposited on the surface of $\mathrm{Ni}_{3} \mathrm{Al}$ micro crystalline foils after 150 min of reaction in pure methanol (sample "K100"- Tab. 1). 

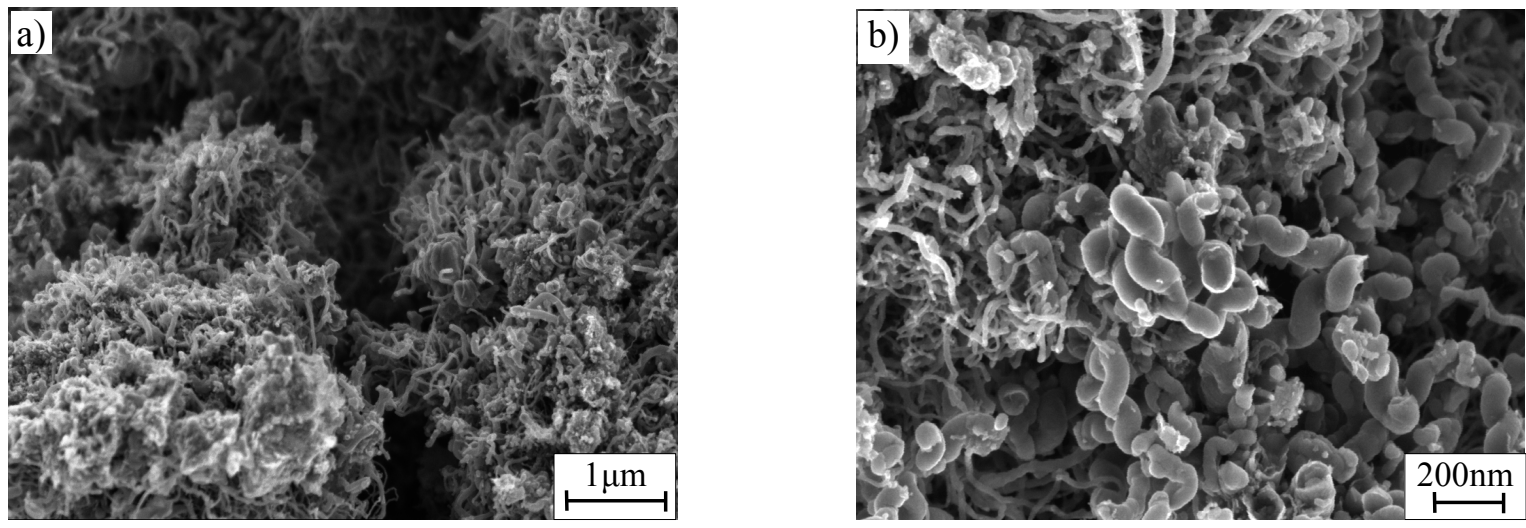

Fig. 4. Morphology of carbon nanofibres (SEM - SE) deposited on the surface of $\mathrm{Ni}_{3} \mathrm{Al}$ nanocrystalline foils after $150 \mathrm{~min}$ of reaction in pure methanol (sample "K100"- Tab. 1)

The X-ray diffraction patterns for reaction products scraped from the $\mathrm{Ni}_{3} \mathrm{Al}$ foil (Fig. 5) demonstrated that the catalytic reaction products contain only pure nickel and graphite. The small nickel particles, probably formed in accordance with the mechanism described in previous reports [6], must serve as an effective catalyst for methanol decomposition, as well as carbon nanofibres, which are expected in common catalyst supports due to their large edges. We also observed that the nanocrystalline $\mathrm{Ni}_{3} \mathrm{Al}$ foils possess a higher amount of nickel particles than their microcrystalline counterparts. This probably results in better catalytic properties for the nanocrystalline materials.

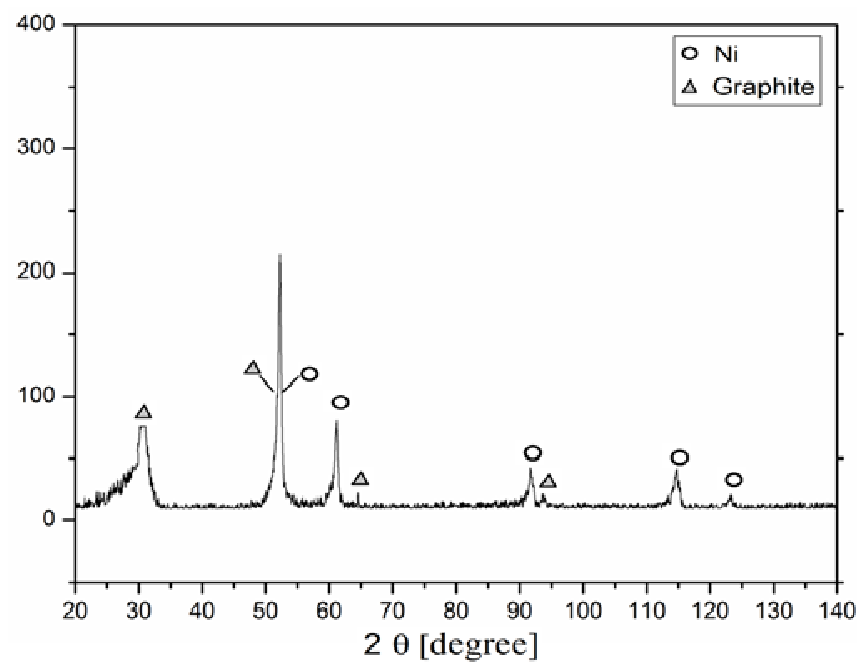

Fig. 5. X-ray diffraction patterns of products scraped off of the surface of $\mathrm{Ni}_{3} \mathrm{Al}$ microcrystalline foils after $150 \mathrm{~min}$ of reaction in pure methanol

\section{Conclusions}

Thin $\mathrm{Ni}_{3} \mathrm{Al}$ foils with micro and nanocrystalline structures demonstrated good catalytic properties in methanol decomposition in a temperature range of $380-580^{\circ} \mathrm{C}$. The existence of carbon nanofibres and nickel nanoparticles forming spontaneously on the foil surfaces during the catalytic reactions was observed. Our main results can be summarised as follows.

1. The methanol conversion to $\mathrm{H}_{2}$ and $\mathrm{CO}$ over flat lustrous $\mathrm{Ni}_{3} \mathrm{Al}$ foil surfaces begins at about $280^{\circ} \mathrm{C}$ for a microcrystalline substrate structure and at about $330^{\circ} \mathrm{C}$ for a nanocrystalline structure.

2. A small addition of water (5\%) to the feed mixture positively influences the methanol conversion on both the micro and nanocrystalline $\mathrm{Ni}_{3} \mathrm{Al}$ catalysts and also has an important influence on the 
selectivity to $\mathrm{H}_{2}$ and $\mathrm{CO}$. For the nanocrystalline foils, we observed a selectivity to $\mathrm{H}_{2}$ that is higher than that to $\mathrm{CO}$, while the opposite trend was observed in the microcrystalline counterparts.

3. Selectivity to the side products $\left(\mathrm{CO}_{2}, \mathrm{DME}\right)$ is very small and decreases with reaction temperature.

\section{Acknowledgement}

The authors gratefully acknowledge financial support for the years 2008-2010 from the Polish Ministry of Science and Higher Education (OR00004905 and R0702502).

\section{References}

[1] V. K. Sikka, S. C. Deevi, S. Viswanathan, R. W. Swindeman, M. L. Santella: Intermetallics (2000), No. 8.

[2] P. Jóźwik, Z. Bojar: Archives of Metallurgy and Materials (2007), 52, 321-327.

[3] Z. Bojar, P. Jóźwik, J. Bystrzycki: Scripta Materialia (2006), 55, 399-402.

[4] M. Demura, K. Kishida, Y. Suga, M. Takanashi, T. Hirano: Scripta Materialia (2002), No. 47.

[5] D. H. Chun, Y. Xu, M. Demura, K. Kishida, D. M. Wee, T. Hirano: Journal of Catalysis (2006), 243, $99-107$.

[6] D. H. Chun, Y. Xu, M. Demura, K. Kishida, M. H. Oh, T. Hirano, D. M. Wee: Catalysis Letters (2006), 106, $71-75$.

[7] G. W. Crabtree, M. S. Dresselhaus, M. V. Buchanan: Physics Today (2004), 12, 39-44.

[8] G.W. Huber, J.W. Shabaker, J.A. Dumesic: Science (2003), 300, 2075-2077.

[9] J. Sehested: Catalysis Today (2006), 111, 102-110.

[10] K. F. Jensen: Chemical Engineering Science (2001), 56, 293-303.

[11] G. Kolb, J. Schurer, D. Tiemann, M. Wichert, R. Zapf, V. Hessel, K. Lowe: Journal of Power Sources (2007), 171, 198-204.

[12] T. Kim, S. Kwon: Chemical Engineering Journal (2006), 123, 93-102.

[13] K. F. Jensen: Chemical Engineering Science (2001), 56, 293-303.

[14] T. Kim, S. Kwon: Journal of Micromechanics and Microengineering (2006), 16, 1760-1768.

[15] T. Kim, S. Kwon: Chemical Engineering Journal (2006), 123, 93-102.

[16] W. Cheng, Ch. Shiau, T. Liu, H. Tung, H. Chen, J. Lu, Ch. Hsu: Applied Catalysis B: Enviromental (1998), 18, 63-70. 